\title{
Associations between aortic pulse wave velocity and aortic and carotid vessel wall thickness in patients with hypertension: assessment with MRI
}

\author{
Anne Brandts, Albert de Roos, Saskia G van Elderen, Lucia J Kroft, Stijntje D Roes, Johan H Reiber, \\ Rob J van der Geest, Jos J Westenberg ${ }^{*}$
}

From 2011 SCMR/Euro CMR Joint Scientific Sessions

Nice, France. 3-6 February 2011

\section{Introduction}

Hypertension puts continuous strain on arteries, resulting in arterial wall alterations such as vessel wall thickening and vessel wall stiffening. Due to the availability of suitable acoustic windows, vessel wall thickness (VWT) is studied traditionally by ultrasound from intima-media thickness in the carotid arteries. Arterial vessel wall stiffness can be expressed by Pulse Wave Velocity (PWV), the propagation speed of the systolic wave front through the aorta. For studying direct associations between PWV and VWT, it is desired to sample VWT in the aorta.

\section{Purpose}

To evaluate associations between aortic and carotid wall thickness and aortic PWV and also with age in subjects with and without hypertension using a comprehensive MRI-approach.

\section{Methods}

Fifteen patients (10 women, mean age $49 \pm 14$ years) with hypertension defined as systolic blood pressure $>140 \mathrm{mmHg}$ and/or diastolic blood pressure $>90 \mathrm{mmHg}$ before antihypertensive medication was instituted, were included. Fifteen age- and gender-matched healthy volunteers without history of cardiovascular disease were included for comparison.

PWV-assessment was performed on 1.5T MRI-scanner (Philips Medical Systems, Best, the Netherlands) according to transit-time method by applying velocity-encoded MRI with high temporal resolution at the aortic arch.

\footnotetext{
Leiden University Medical Center, Leiden, Netherlands

Full list of author information is available at the end of the article
}

At the same day, aortic and carotid vessel wall imaging was performed on 3T MRI-scanner (Philips Medical Systems, Best, the Netherlands) using three-dimensional (for aorta) and multi-two-dimensional (for carotid artery) dual-inversion black-blood gradient-echo sequences with $0.5 \times 0.5 \mathrm{~mm}^{2}$ in-plane resolution, spectral-selective fat suppression and navigator respiratorycompensation (for aorta). Ten slices (aorta) and eight slices (common carotid artery) were analyzed using inhouse developed software VesselMass. Luminal and outer wall boundaries were manually segmented. Mean VWT was computed and indexed for Body Surface Area (BSA):

$\Sigma[($ area vessel wall $\times$ slice thickness $) /$ total number of slices]/BSA.

\section{Results}

Hypertensive patients presented with higher PWV and aortic and carotid VWT than healthy volunteers (Table 1). Associations between PWV, aortic and carotid VWT and with age are presented in Figure 1. PWV and aortic and carotid VWT were all significantly associated with age, and all associations were not different between patients and volunteers. Association between aortic PWV and aortic VWT was stronger than for aortic PWV and carotid VWT. Finally, aortic VWT correlated with carotid VWT.

\section{Table $1 \mathrm{MRI}$ results}

\begin{tabular}{llll}
\hline & Hypertension & Volunteers & p-value t-test \\
\hline Aortic PW (m/s) & $7.0 \pm 1.4$ & $5.7 \pm 1.3$ & 0.011 \\
Aortic wall thickness/BSA & $0.12 \pm 0.03$ & $0.10 \pm 0.03$ & $<0.001$ \\
Carotid wall thickness/BSA & $0.04 \pm 0.01$ & $0.03 \pm 0.01$ & 0.014
\end{tabular}




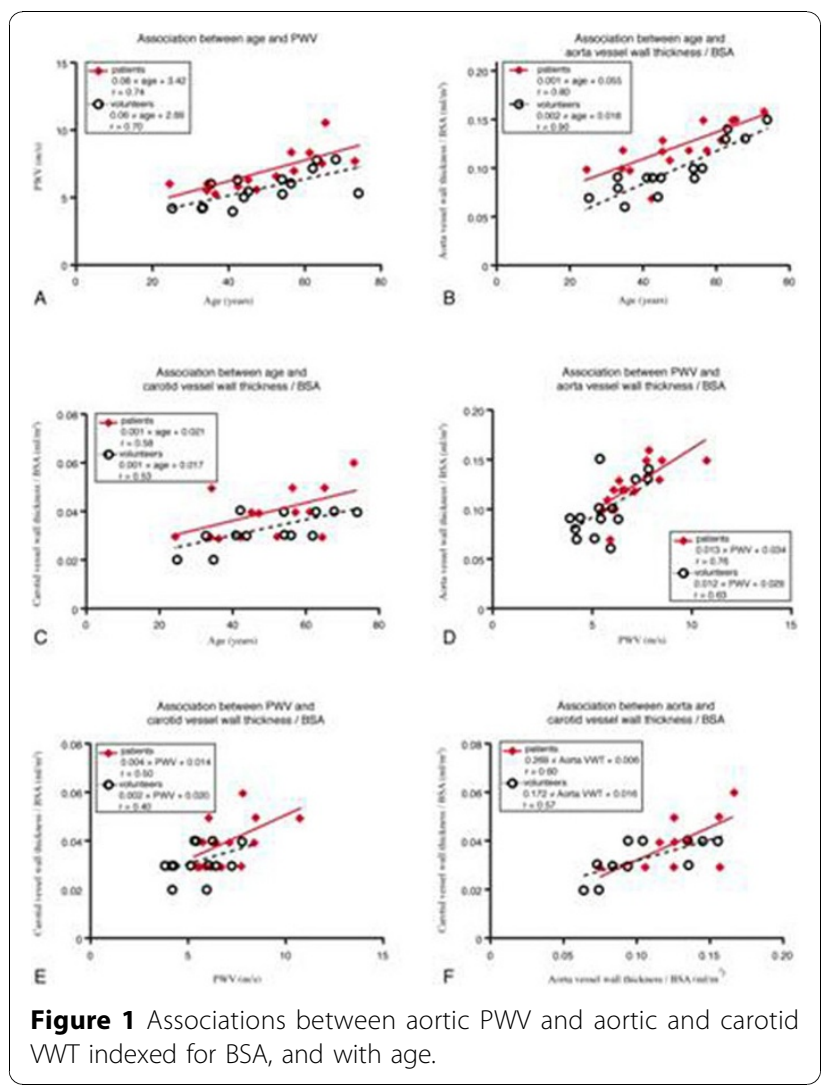

\section{Conclusions}

MRI presents associations between aortic and carotid VWT and aortic PWV, and all parameters are increased in patients with hypertension versus age- and gendermatched healthy volunteers.

Published: 2 February 2011

doi:10.1186/1532-429X-13-S1-P72

Cite this article as: Brandts et al:: Associations between aortic pulse wave velocity and aortic and carotid vessel wall thickness in patients with hypertension: assessment with MRI. Journal of Cardiovascular Magnetic Resonance 2011 13(Suppl 1):P72.
Submit your next manuscript to BioMed Central and take full advantage of:

- Convenient online submission

- Thorough peer review

- No space constraints or color figure charges

- Immediate publication on acceptance

- Inclusion in PubMed, CAS, Scopus and Google Scholar

- Research which is freely available for redistribution 